\title{
RECONSTRUCTION OF HIND FOOT DEFECTS;
}

\section{A SIMPLIFIED WORKABLE SOLUTION}

Dr. Muhammad Rizwan Aslam, Dr. Aizaz Saleem Khan, Dr. Ibrahim Farooq Pasha, Dr. Rizwan Ullah Taj.

ABSTRACT.....BACKGROUND: Reconstruction of traumatic as well as non-traumatic hind foot defects is always a challenging task. We share here a simple and practical protocol (working solution) to select the most suitable method for soft tissue coverage of hind foot defects, customizable for every patient. METHODS: We carried out this study, in our department on 75 cases from March 2009 to May 2012. All cases with wound/defect in hind foot area were included. Majority of cases were traumatic rest included cases of malignancy, Trophic ulcers, infection. Patient's data including age, sex, site of injury, mode of injury, extent of injury (isolated or combined), if combined structures involved, type of wound, management of wound, wound healing time and complications were noted. Once optimal wound conditions were achieved the best possible reconstructive option was selected. The various reconstructive options include VAC therapy, Skin graft, local transposition flap, perforator based flapspedicled faciocutaneous/ muscle flaps, intrinsic foot muscles, Medial plantar artery flap and distant flaps like cross leg flap and micro vascular free flaps. RESULTS: All patients had satisfactory and stable reconstruction. They were ambulating freely by 4-6 weeks post operatively. There were few complications like patchy graft loss, peripheral flap necrosis, flap congestion, but none was serious and did not require repeat surgery. CONCLUSION: The simplified protocol followed by us is a practical customizable solution for difficult task of hind foot reconstruction. The choice of one or multiple techniques will vary from time to time from one surgeon to another depending upon his or her experience and liking.

Key words: Hind foot defects, reconstruction, skin grafting, lateral calcaneal flap' supramalleolar flap' reverse sural artery flap, Free tissue transfer.

Article Citation

Aslam MR, Khan AS, Pasha IF, Taj RU.Reconstruction of hind foot defects; a simplified workable solution. Professional Med J 2013;20(4):606-616.

\section{INTRODUCTION}

The hind foot includes weight bearing heel, posterior heel around tendo Achilles, lateral, medial and anterior surfaces of ankle joint Fig 1. This area inherently has lack of soft tissue. Soft tissues loss, whether from recent trauma, surgical extirpation of malignancy, or from chronic lesions are difficult to cover and require a well vascularized robust and durable reconstruction. It has always posed a daunting challenge for plastic surgeons.

With a better understanding of the vascular anatomy of the leg, the availability of microsurgical techniques and ingenuity and hard work of various plastic surgeons, numerous flaps have been described. From this wide array of flaps one can choose a flap that is easy to execute quickly and provide durable coverage for the defect with minimal donor site morbidity. The foremost requirement is an optimal wound free of infection which can be safely reconstructed. This needs thorough debridement and management of initial wound with dressing and/or appropriate antibiotics. Followed by, reassessment of the defect in 3D. Finally, selection of the most reliable method, that has least morbidity of recipient and donor site, and which is best possible way of rehabilitating the patient.

This study was carried out to devise a simple and practical mechanism that we could follow for the management of various hind foot defects, acute or chronic. This has enabled us to reliably select the best and most practical option for reconstruction in this difficult zone, with a cosmetically acceptable, durable and longstanding result.

\section{MATERIALS AND METHODS}

We carried out this study, in our department on 75 cases from March 2009 to May 2012. All cases with wound/defect in hind foot area were included. Majority of cases were traumatic rest included cases of malignancy ${ }^{32}$ (majority squamous cell carcinoma, one case was of Marjolin's ulcer), Trophic ulcers, Diabetic 
foot/necrotizing fasciitis, electric burns, chronic osteomyelitis and severe contractures which after release resulted in significant soft tissue defects requiring import of soft tissue for coverage [Table-l]. Patient's data including age, sex, site of injury, mode of injury, extent of injury (isolated or combined), if combined structures involved, type of wound, management of wound, wound healing time and complications were noted. Most of the wounds in this area are contaminated. Thorough wound toilet and debridement, fixation of fractures (if required done by orthopedic unit) and immobilization was given the foremost importance and in majority of these cases initial debridement was carried out by the senior author and not left to residents. Saline soaked dressings were done, limb elevation was given, daily dressings were carried out. VAC therapy (vaccum assisted closure) was used in majority of patients once infection was settled to reduce the number of change of dressing and reduce patient discomfort. This also reduced the workload. VAC was changed every 3 to 5 days and every time wound was assessed by senior author for suitability of reconstruction. Once optimal wound conditions were achieved, the wound was reassessed, a record of the site, size, depth, shape and exposed structures was made. After this three dimensional assessment on the basis of age, sex and profession of the patient and keeping in mind the condition of the surrounding structures, the best possible reconstructive option was selected which best suited that patient. The various reconstructive options include VAC therapy followed by simple skin graft, local transposition flap, perforator based

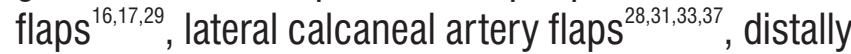
based sural artery flap $p^{14,2,2,21,23,24,25,39}$, Supramalleolar flap $^{19,34}$, distally based fasciocutaneous perforator based posterior calf flap ${ }^{1,1729}$, reverse soleus muscle flap $^{18}$, Abductor halluces muscle flap ${ }^{27,40}$, Flexor digitorum brevis flap $\mathrm{p}^{35,40}$, Medial plantar artery flap(sensate) ${ }^{1,22}$ and distant flaps like cross leg flap and

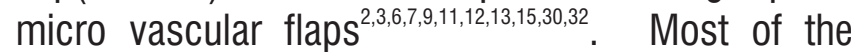
patients were operated under spinal anesthesia (except free flaps and few other younger patients). Immobilization was done depending upon the requirements and type of flap used.

\begin{tabular}{|c|c|c|}
\hline Cause & Cases & \%age \\
\hline Road traffic accident & 30 & 40 \\
\hline Degloving / Wheel spoke injury & 13 & 17.33 \\
\hline Gunshot wound / Splinter injuries & 1 & 1.33 \\
\hline Squamous cell carcinoma (one case of marjolin's ulcer in burn scar) & 5 & 6.66 \\
\hline Trophic ulcers & 3 & 4 \\
\hline Necrotizing fasciitis / diabetic foot wounds & 14 & 18.66 \\
\hline Electric burns & 3 & 4 \\
\hline Chronic osteomyelitis / chronic infection & 5 & 6.66 \\
\hline Severe contractures / Tendo Achilles lengthening & 1 & 1.33 \\
\hline Total & 75 & \\
\hline
\end{tabular}

Table-I. Cause of defect. 
The age of patients ranged between 1.5 years to 67 years, with mean age 35 years. 52(69.33\%) were male patients and 23(30.66) were females. Male to female ratio was 2.26:1. Isolated injuries (injuries only over the hind foot) were present in 41 patients (54.66\%) and combined injuries (injuries to hind foot and surrounding lower leg or mid/forefoot) in 34 patients (45.33\%) [Table-II] Split thickness skin grafting was done in 12 patients (isolated $n=5$, combined $n=7$ ), distally based superficial sural artery flap done in 20 cases (isolated $n=13$, combined $n=7$ ), Lateral calcaneal artery flaps done 9 (isolated $n=9$ ), Free flaps done in 4 cases (Free Antero lateral thigh flap $n=2$, Radial artery free flap $n=2$ ), Medial heel flaps 2 in isolated injuries, Perforator based flaps 3 (all combined $n=3$ ), Cross leg gastrocnemius flaps 2 (isolated $n=1$, combined $n=2$ ) and VAC therapy followed by STSG done in 23 cases (isolated $n=10$, combined $n=13$. [Table-II]. Two cases with large complex defects had Sural flap combined with STSG.

\begin{tabular}{|c|c|c|c|c|}
\hline Reconstruction technique & \multicolumn{3}{|c|}{ No of cases } & Complications \\
\hline STSG & 12 & $\begin{array}{l}\text { Isolated } \\
\text { Combined }\end{array}$ & $\begin{array}{l}n=5 \\
n=7\end{array}$ & Nil \\
\hline VAC Therapy \& STSG & 23 & $\begin{array}{l}\text { Isolated } \\
\text { Combined }\end{array}$ & $\begin{array}{l}n=10 \\
n=13\end{array}$ & Patchy graft loss/infection- 6 patients \\
\hline Sural Flap & 17 & $\begin{array}{l}\text { Isolated } \\
\text { Combined }\end{array}$ & $\begin{array}{l}n=14 \\
n=3\end{array}$ & Marginal flap necrosis- 3 patients \\
\hline Sural Flap \& STSG & 3 & $\begin{array}{l}\text { Isolated } \\
\text { Combined }\end{array}$ & $\begin{array}{l}n=0 \\
n=3\end{array}$ & Patchy graft loss 1 patient \\
\hline Lateral Calcaneal Flap & 9 & $\begin{array}{l}\text { Isolated } \\
\text { Combined }\end{array}$ & $\begin{array}{l}n=9 \\
n=0\end{array}$ & Distal flap necrosis- 1 patient \\
\hline Supramalleolar flap & 2 & $\begin{array}{l}\text { Isolated } \\
\text { Combined }\end{array}$ & $\begin{array}{l}n=2 \\
n=0\end{array}$ & Nil \\
\hline Free Flap & 4 & $\begin{array}{l}\text { Isolated } \\
\text { Combined }\end{array}$ & $\begin{array}{l}n=0 \\
n=4\end{array}$ & Nil \\
\hline Cross leg Gastroc Flap & 2 & $\begin{array}{l}\text { Isolated } \\
\text { Combined }\end{array}$ & $\begin{array}{l}n=1 \\
n=1\end{array}$ & Partial graft loss over muscle- 1patient \\
\hline Perforator Flap & 3 & $\begin{array}{l}\text { Isolated } \\
\text { Combined }\end{array}$ & $\begin{array}{l}n=1 \\
n=2\end{array}$ & Nil \\
\hline
\end{tabular}

Table-II. Method of reconstruction \& complications.

First change of dressing was done on day 3 or 5 depending upon the type of reconstruction followed by daily or alternate day dressing. Sutures/staples were removed around day 10. Pressure dressings (Elastocrepe bandage) was started on the $10^{\text {th }}$ day with gradual dependency (if no complications) started between 12 to 15 days and increasing it till the $21^{\text {st }}$ day. Active and passive physiotherapy of joints around ankle was also started on the 10th day. After 21 days gradual mobilization was started with intermittent weight bearing, making the patient to do all his activities at around one and half months. In between the weight bearing, patients were advised elevation of limbs. Patients were also advised to keep a constant watch over the graft for congestion and breakage and in flaps, for congestion and softening. Daily massage and use of special footwear (silicone) were also explained to the patient.

Follow-up was carried out for the presence of pain over 
the donor or recipient site, aesthetic appearance of donor and recipient site, loss and restriction of movements, loss of sensations by division of sural nerve or superficial peroneal nerve and scar complications. In the patients having injury over the weight bearing part of the heel, silicone heel pads and protective special footwear was advised. Average follow up of the patients was 6 months and longest follow-up was 2.5 years.

Reconstructive options:

1. Split thickness skin graft

2. Media plantar artery sensate flap

3. Reverse Sural neurofasciocutaneous flap

4. Supramalleolar

5. Lateral calcaneal flap

6. Perforator based flap from distal half leg

7. Reverse soleus muscle flap

8. Pedicled small muscles of foot (Flexor/Extensor digitorum brevis, Abductor halluces, Abductor/Flexor digiti minimi)

9. Cross leg gastrocnemius flap

10. Microvascular free tissue transfer

Table-III. Reconstruction options

\section{RESULTS}

All patients had satisfactory and stable reconstruction. We had our share of complications, but none of them were severe enough to require redo surgery. This further substantiates the efficacy and practicality of the simple protocol that we propose. Patchy graft loss/ minor wound infection was noted in 6 out of total 38 patients in whom Skin graft was used as an isolated or combined procedure with a flap. All were managed with appropriate antibiotic after culture sensitivity and all such wounds healed without necessitating repeat surgery. 3 out of total 20 Sural flaps developed distal flap necrosis which was minimal and after delayed debridement healed secondarily with dressings alone. 1 lateral calcaneal flap also developed distal necrosis but since all were performed for isolated, relatively smaller wounds so it too healed by secondary intention. One cross leg gastrocnemius muscle flap partially lost overlying skin graft but due to good blood supply and absence of infection it too healed with dressings alone. All patients by 6 to 8 weeks were ambulating freely. Sural flap is well known for its venous congestion and it happened the same in $70 \%$ of our cases ${ }^{39}$, but with appropriate use of external compression and elevation the oedema and swelling subsided. 6 out of 20 sural flaps were thinned in two stages on patient request due to unsightly and cumbersome bulk, after a delay of minimum 1 year. Cross leg gastrocnemius muscle flaps with skin graft were done during early phase of this study. All were done in younger patients under 30 years of age. Pedicle division was done after three weeks and they were kept in special pop cast during this time. Post operatively none developed any joint stiffness or prolonged restriction of Rom of joints. All those with involvement of weight bearing heel had painful weight bearing for between 6 to 9 months. Two cases developed breakdown of reconstruction over weight bearing heel due to their own carelessness. They started using normal footwear too early, and did not use Silicone heel pads advised to them, resulting in ulceration and breakdown of suture line in the flaps. One of them required debridement and small skin graft whereas the other one healed after debridement by secondary intention.

All patients after discharge initially had weekly follow up visits for one month followed by 2 to 6 weekly visits for next 6 months varying according to the type of reconstruction and presence of symptoms/ complications. The skin grafts were only used on areas other than weight bearing heel. Majority about 85\% developed minor blistering and break down during initial recovery phase between 2nd to 4th weeks. They were all prescribed neomycin/ polymixin B ointment for application as and when required and all grafts became stable and mature by 4 to 6 weeks. All grafted patients were prescribed emollients for at least six months use. 9 out of total 38 skin grafts developed signs of hypertrophic scarring, which were identified at an early stage during follow up period and were managed with massage, Alhydran gel, Aloe vera 
cream and silicone gel sheeting, combined with prolonged external compression. All those patients who started ambulation early and did not follow the instructions about good tight external compression developed purplish and pinkish discoloration and congestion which took between 6 to 9 months to settle. All the four free flaps survived in toto without any complication. Oedema and swelling persisted for few months but settled with time and patients were very satisfied with the results. Two of these four were for malignancy, whereas 3 sural flaps were done for other malignant cases. Complete resection and clear resection margins were confirmed by histopathological examination. All flaps withstood the postoperative radiotherapy well without any breakdown or any other complication. In the long term follow up all patients had stable and durable reconstruction with acceptable cosmetic results. All were ambulating freely. Use of special footwear and silicone heel pads were ensured in all cases having flap over weight bearing heel.

\section{DISCUSSION}

Hind foot is the area from a horizontal line through ankle joint to vertical axis of talonavicular joint(Fig 1). The area is inherently deficient of soft tissue except over heel where there is good padding of fat and thick keratinized skin. Any breakdown or loss of skin due to Insult to this area whether traumatic or infective results in exposure of bone(malleoli/calcaneum), tendons or joint capsule. Tendons and joint capsule inherently being relatively less vascular pose special problems in healing or formation of healthy granulation tissue. It is a proven fact that best reconstruction and results are seen when initial debridement is done during first 6 hours and if time and theatre space allows primary reconstruction gives the quickest healing with minimal complications and significantly reduces the patient's hospital stay. This is not usually possible all the time. One most important factor in this regard is the degree of contamination and the amount of dead and devitalized tissue in the wound. This is most commonly seen in crush injuries and high velocity missile injuries. Uncontrolled diabetes mellitus and necrotizing fasciitis is another condition where very rapid and extensive soft tissue necrosis is seen. Degloving injuries most of which are wheel spoke injuries is another devastating injury which results in at times avulsion and or loss of significant soft tissue covering of the hind foot. The situation is sometimes further complicated by avulsion of Tendo Achilles tendon from its insertion into the calcaneum ${ }^{15}$.

As far as the weight bearing heel is concerned, there is no doubt that the best reconstruction is with medial plantar artery flap. The overwhelming pros of this flap are, like tissue replacing like tissue, it being sensate and minimal donor site morbidity because it is at the non-weight bearing part of the sole. The only catch is its difficult dissection and execution. There was a time when muscle flaps with overlying skin graft ${ }^{6,7,30}$ were very popular but with time we have realized that skin graft whether meshed, unmeshed or even thicker grafts are never strong enough to withstand the weight and the shearing of the foot wear and invariably breakdown at some stage after ambulation. So this option is very infrequently used nowadays and that too in situations where there are no other practical options available $^{3,4,5,6,7,9,12,24}$.

Fasciocutaneous flaps like Sural artery flap or free flaps are the next best options. They take longer to get stabilized over the exposed calcaneum. One major drawback is that they are mostly insensate until special care is taken and a suitable donor nerve is anastamosed to flaps cutaneous nerve and thus is rendered sensate. Kuran,I et al4 in their study have shown that there is no long term difference between sensate and insensate flaps as regards to their stability and durability. No significant difference was found in gait and weight bearing dynamics in two types of flaps. Bursa formation between bone and flap is also a consideration which can be prevented by delaying the weight bearing and shearing force of foot wear till the 
flap has firmly fixed with the bone. Sometimes it helps to curette the exposed bone surface to make it rough so that firm fibrotic bridging connections develop between flap and the bone.

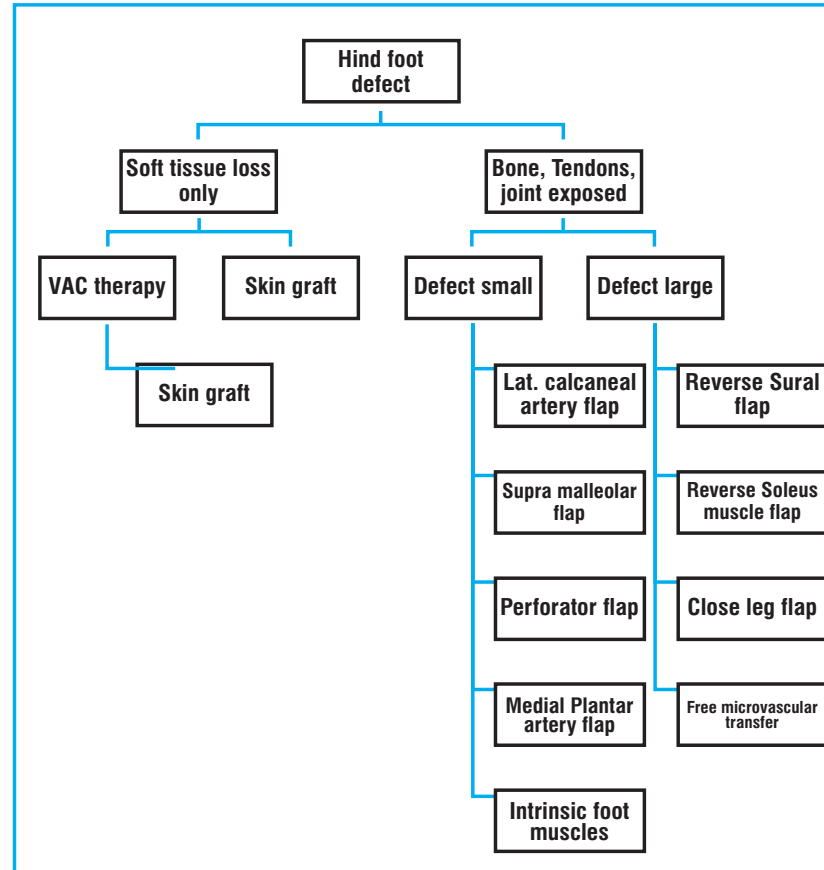

Fig 1: Simplified hierarchy chart for hind foot reconstruction

Sural fasciocutaneous flap ${ }^{14,23,24,25}$ has been a work horse for the reconstruction of this particular area for years. It is highly reliable, soft pliable skin is imported in to the defect. Only because of it being dependant on reverse flow vasculature and relatively smaller vessel size it inherently has potential for venous congestion in initial days. If underlying haematoma is avoided, tense suture lines are not there, pedicle twist/compression is avoided and foot is adequately elevated during initial 7 days*, this congestion can be reversed very quickly and does not cause detrimental effects on flap survival. Flap delay, wide pedicle and avoiding the tunneling of flap pedicle are all the techniques important in preventing flap related complications ${ }^{14,39}$. Whenever defect is small and primary closure of donor site is possible it gives an acceptable cosmetic result. The only drawback of this flap is unsightly skin grafted donor site. In our study we performed 20 Sural flaps out of 75 cases. Three out of these were for large complex wounds, where we used the largest possible flap for coverage of the critical and deeper defect and rest of the surrounding area was skin grafted. All the flaps survived due to good planning and execution. Only three flaps inspite of this developed marginal necrosis but it was small area which healed with secondary intention without requiring any repeat surgery. Five cases were for tumour ${ }^{32}$, three were primary biopsy proven squamous cell carcinomas and two were marjolin's ulcers in chronic scar tissue. Three were treated with Sural flaps, one was reconstructed with Radial forearm free flap and for largest one Anterolateral thigh flap was done. ALTF was bulky flap initially but oedema and bulk reduced after postoperative radiotherapy. Except the ones for marjolin's ulcers rest three were post operatively irradiated and all three withstood radiation well.

Majority 44 out of 75 were acute traumatic cases, resulting from RTA, Degloving (wheel spoke injury and gunshot wounds [Table-l]. Amount of contamination varied in different cases but extreme importance was given to initial debridement preferably within first 6 hours where ever possible. Almost all debridements were done by the senior author himself. Those wounds with minimal or no contamination and minimal dead, devitalized tissue were treated with VAC technique ${ }^{8,10,26}$ immediately after initial debridement and they tend to heal much quicker than the ones which were treated initially for few days with repeated dressings and once they were infection free either reconstruction was carried out or VAC technique was used till they were in optimal condition for reconstruction. VAC therapy was used in almost all traumatic and majority of infective cases and it significantly reduced the infection rate, reduced number of days that antibiotics were used and also reduced the work load as VAC was changed between day 3 to 5 . At every change of VAC senior author inspected the wound and decision for proceeding with reconstruction was made when wound and overall patient's condition was found 
optimal. The reconstruction protocol that we used [Fig 2] has been very helpful in making the tailor made right decision for every individual wound and patient. The guiding factors were, age, sex, profession of the patient, site, size and complexity of the wound, three dimensional assessment of the defect and simply

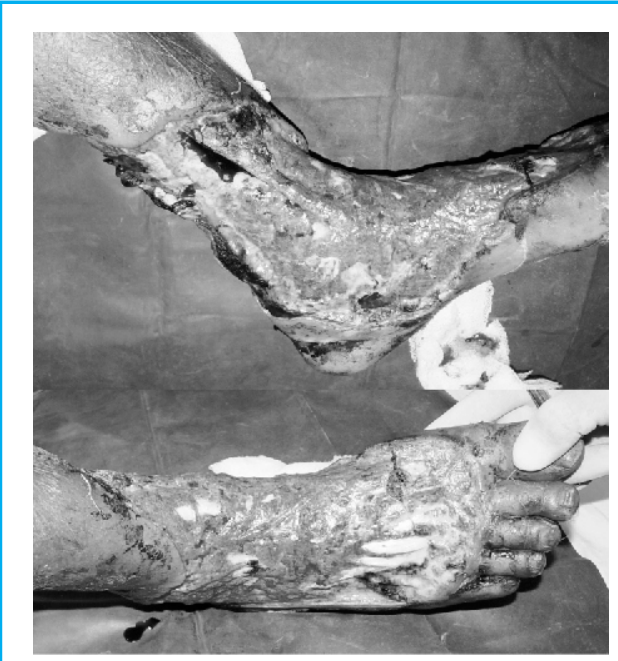

Fig-1A

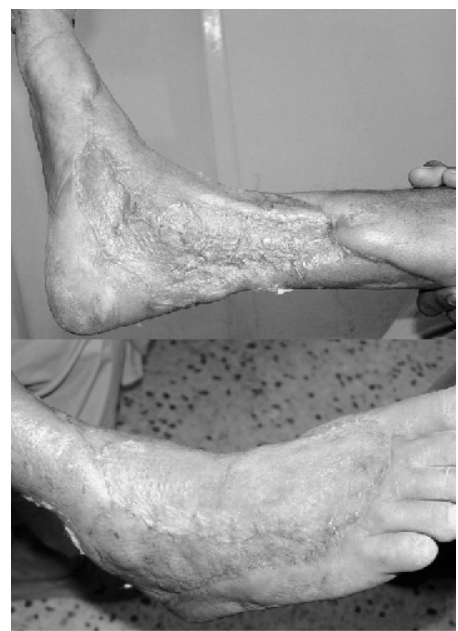

Fig-1B

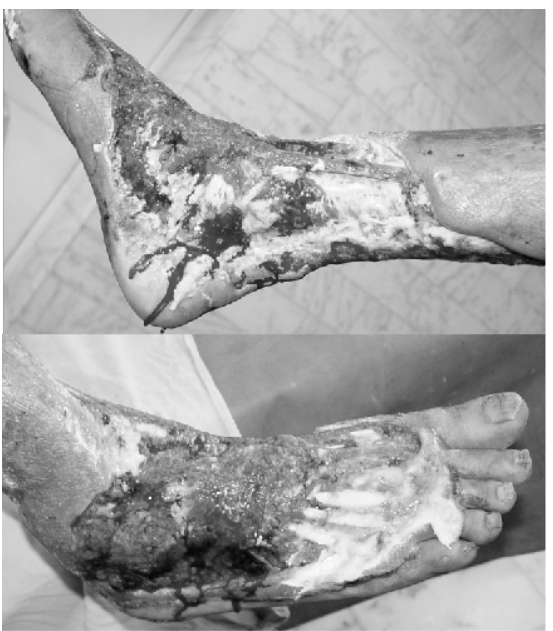

Fig-1C

Figure 1-A: An old diabetic man with necrotizing fasciitis ankle and foot.

Figure 1-B: Patient after 12 days of VAC therapy.

Figure 1-C: Patient after 19 days of vac therapy treated with split thickness skin graft. Late stable result.

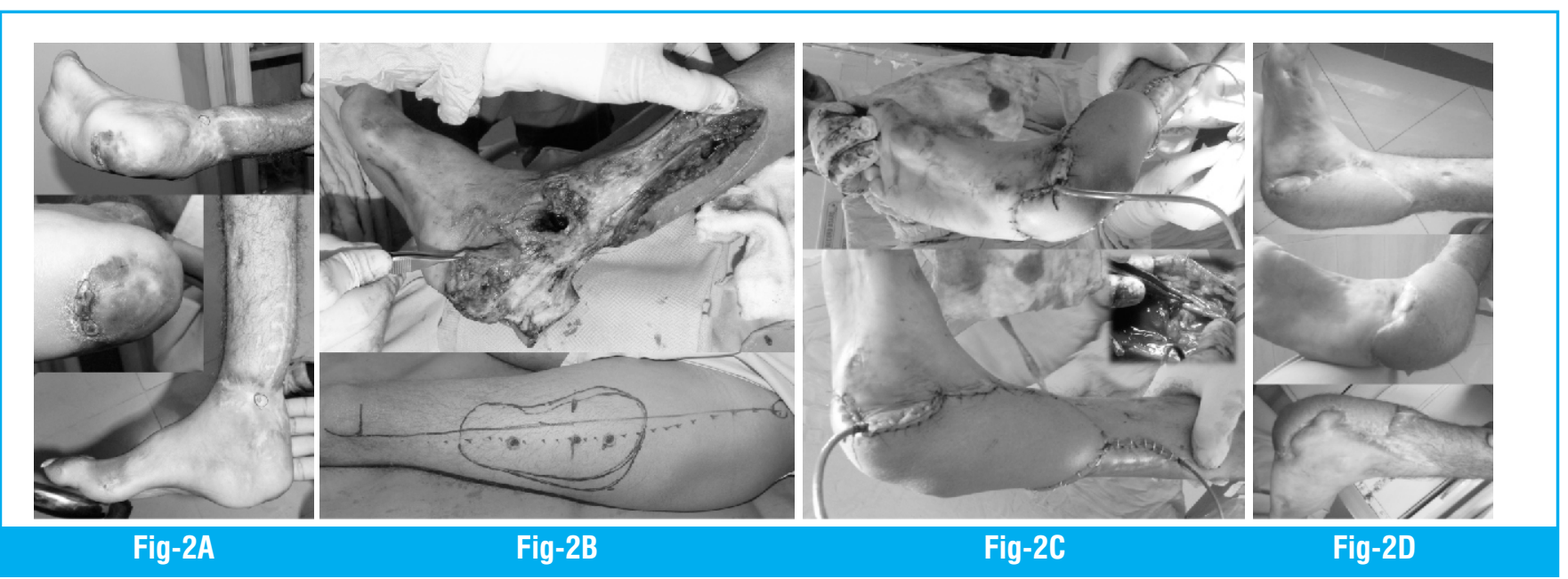

Figure 2-A: A young man with chronic osteomyelitis of distal tibia with scarred skin grafted painful heel, which broke down frequently.

Figure 2-B: Upper: Intraoperative photo after saucerization of osteomyelitis, excision of all scarred problematic tissue. Lower: planned Free Antero lateral thigh flap.

Figure 2-C: $\quad$ Flap insetting completed intraoperative. Inset: Microvascular anastomosis to Posterior tibial vessels.

Figure 2-D: The healed flap with good heel coverage at Three months. 
referring to the protocol it became very easy to make the right choice for the right patient and wound.

Trophic ulcers and diabetic wounds/necrotizing fasciitis is another major cause of wounds over the hind foot ${ }^{8,1,12,13}$. In majority of diabetic cases the loss of tissue was extensive extending into mid/forefoot and up into the leg. Due to concomitant peripheral vascular disease and multiple comorbid conditions in these

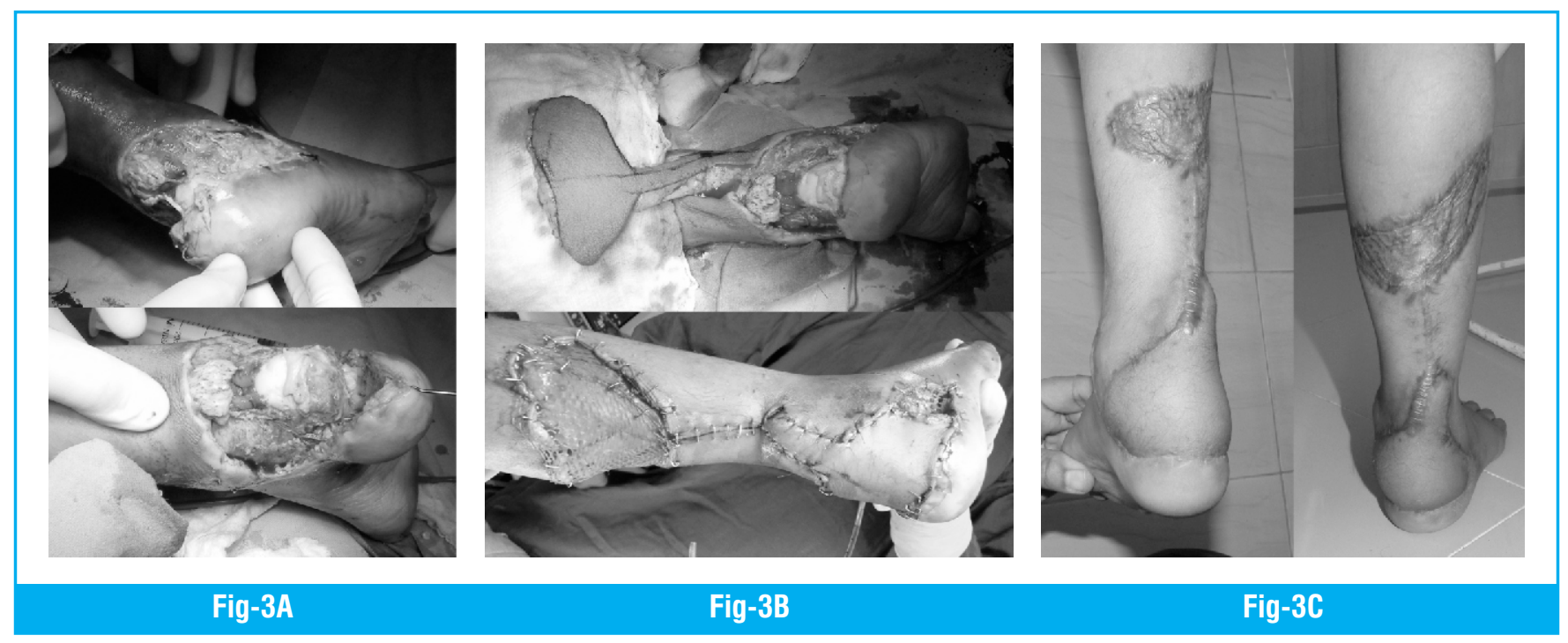

Figure 3-A: $\quad$ Young boy with wheel spoke injury, loss of soft tissue and avulsion of heel pad.

Figure 3-B: $\quad$ Upper: Sural neurofasciocutaneous flap raised. Lower: Flap inset at completion with skin graft at donor site.

Figure 3-C: $\quad$ Excellent stable result at 6 months. Unsightly donor site is visible.

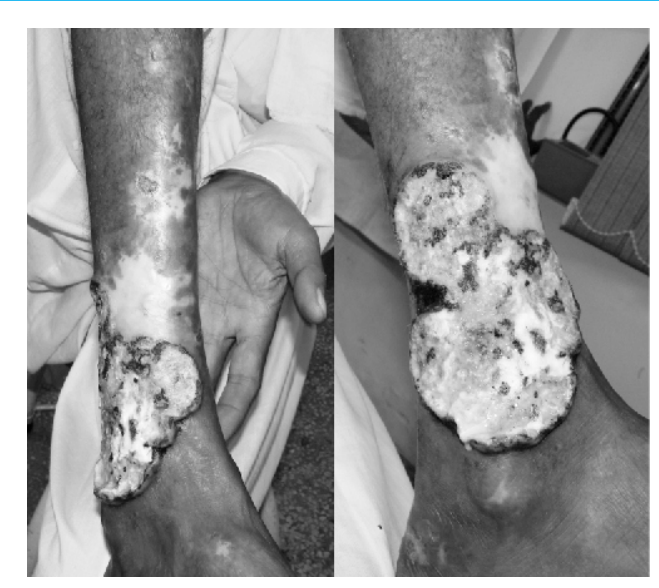

Fig- 4 A

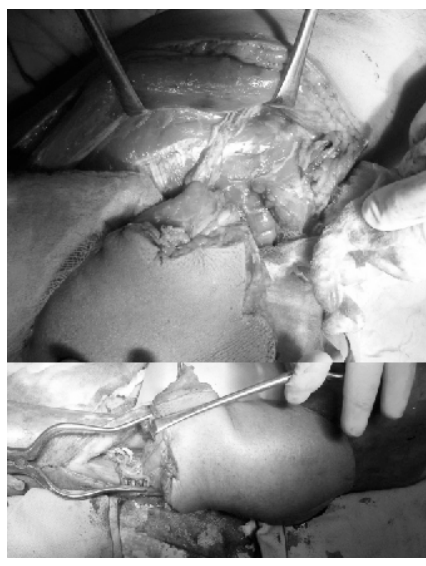

Fig-4B

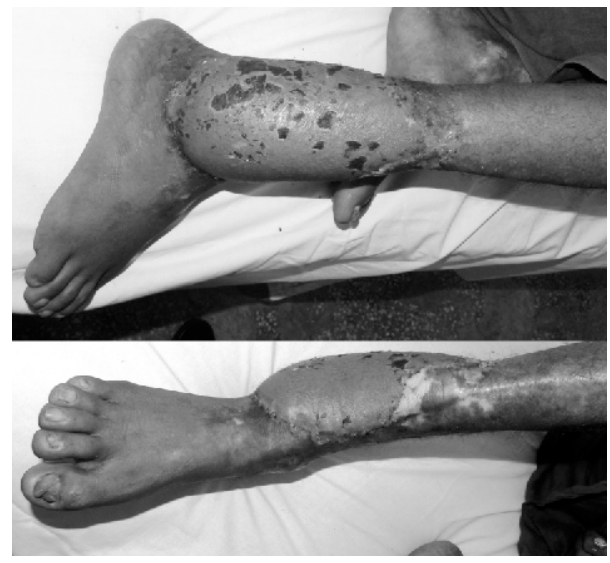

Fig-4C

Figure 4-A: Squamous cell carcinoma over lateral ankle and lower leg.

Figure 4-B: $\quad$ Upper: Free ALTF being elevated with visible vascular pedicle. Lower: Flap inset after tumour resection with visible microvasculay anastomosis.

Figure 4-C: $\quad$ Well healed flap at three weeks postop. 
diabetics, majority of whom were in older age group, the number of surgeries needed, were to be kept to minimum and lengthy and complicated flap surgeries were technically not possible. We have found with extensive experience with VAC therapy that even in larger wounds with exposed tendons / bone, once the tissue necrosis and the infection is controlled, VAC dressings ${ }^{8,10,26}$ can prepare the wounds very well for a successful split thickness skin graft. Once the wound and the patient are in optimal state, VAC therapy can be very easily managed as an outdoor case with either static or ambulatory VAC system. The patient only has to come in outdoor clinic for a change of VAC dressing every 4-5 days. The intrinsic small muscles of foot all are also viable options in selective patients with small wounds ${ }^{27,35,36,40}$. The once much propagated overwhelming benefit of a vascularized muscle flap with skin graft $^{6,7,30}$ in the presence of severe osteomyelitis is now accepted with guarded skepticism. Demirates, $\mathrm{Y}$ et $\mathrm{al}^{30}$ in their study have concluded that the well vascularized free fasciocutaneous flap also imports good blood supply into the relatively ischaemic wound and their better cosmetic look and robust skin coverage surmounts the benefits of once popular muscle with skin graft. Ozkan,0 et $\mathrm{al}^{13}$ have shown in their study that in the absence of significant comorbid conditions flaps heal well in these diabetics ${ }^{* *}$. There is no contraindication to such procedures in diabetics, especially when other options are not feasible or results are anticipated to be too inferior.

\section{CONCLUSION}

It will always remain a fact that hind foot reconstruction, a challenging task now has a wide array of reconstructive options. The choice of one or multiple techniques will vary from time to time from one surgeon to another depending upon his or her experience and liking.

Copyright@ 29 Jan, 2013.

\section{REFERENCES}

1. Cormack GC, Lamberty BGH. The Arterial Anatomy of Skin Flaps. London: Churchill Livingstone; 1986.

2. Hallock, G. G., Rice, D. C., Keblish, P. A., and Arangio, G. A. Restoration of the foot using radial forearm flap. Ann. Plast. Surg. 20: 14, 1988.

3. Gidumal, R., Carl, A., Evanski, P., Shaw, W., and Waugh, T.R. Functional evaluation of nonsensate free flaps to the sole of the foot. Foot Ankle $7: 118,1986$

4. Kuran, I., Turgut, G., Bas, L., et al. Comparison between sensitive and nonsensitive free flaps in reconstruction of the heel and plantar area. Plast. Reconstr. Surg. 105:574, 2000.

5. Santanelli, F., Tenna, S., Pace, A., and Scuderi, N. Free flap reconstruction of the sole of the foot with or without sensory nerve coaptation. Plast. Reconstr. Surg. 109:2314, 2002.

6. May, J. W., Jr., Halls, M. J., and Simon, S. R. Free microvascular muscle flaps with skin graft reconstruction of extensive defects of the foot: A clinical and gait analysis study. Plast. Reconstr. Surg. 75: 627, 1985.

7. May, J. W., Jr., Lukash, F. N., and Gallico, G. G., III. Free latissimus dorsi muscle flap with skin graft for treatment of traumatic chronic bony wounds. Plast. Reconstr. Surg. 73: 641, 1984.

8. Clare MP, Fitzgibbons TC, McMullen ST, Stice RC, Hayes $D F$, Henkel $L$. Experience with the vacuum assisted closure negative pressure technique in the treatment of non-healing diabetic and dysvascular wounds. Foot Ankle Int. 2002 0ct;23(10):896-901

9. Sonmez, A., Bayramicli, M., Sonmez, B., and Numanoglu, A. Reconstruction of the weight-bearing surface of the foot with nonneurosensory free flaps. Plast. Reconstr. Surg. 111:2230, 2003.

10. Flack S, Apelqvist J, Keith M, Trueman P, Williams D. An economic evaluation of VAC therapy compared with wound dressings in the treatment of diabetic foot ulcers. J Wound Care. 2008 Feb;17(2):71-8.

11. Hong JP. Reconstruction of the diabetic foot using the 
anterolateral thigh perforator flap. Plast Reconstr Surg. 2006; 117:1599-1608.

12. Musharrafieh R, Saghieh S, Macari G, Atiyeh B. Diabetic foot salvage with microsurgical free-tissue transfer. Microsurgery 2003;23:257-261.

13. Ozkan 0 , Coskunfirat OK, Ozgentas HE. Reliability of free flap coverage in diabetic foot ulcers. Microsurgery 2005;25: 107-112.

14. Yilmaz, M., Karatas, O., and Barutcu, A. The distally based superficial sural artery island flap: Clinical experiences and modifications. Plast. Reconstr. Surg. 102: 2358, 1998.

15. Kuo, Y. R., Kuo, M. H., Chou , W. C., Liu, Y. T., Lutz, B. S., and Jeng, S. F. One-stage reconstruction of soft tissue and Achilles tendon defects using a composite free anterolateral thigh flap with vascularized fascia lata: Clinical experience and functional assessment. Ann. Plast. Surg. 50: 149, 2003.

16. Ozdemir R, Kocer U, Sahin B, Oruc M, Kilinc H, Takdemir I. Examination of the skin perforators of the posterior tibial artery on the leg and the ankle region and their clinical use. Plast Reconstr Surg. 2006;117:16 19-1630

17. Blondeel, P. N., Morris, S. F., Hallock, G. G., and Neligan, P. C. (Eds.), Perforator Flaps: Anatomy, Technique, and Clinical Applications. St. Louis: Quality Medical, 2006.

18. Townsend, P. L. G. An inferiorly based soleus muscle flap. Br. J. Plast. Surg. 31: 210, 1978.

19. Masquelet, A. C., Beveridge, J., Romana, C., and Gerber C. The lateral supramalleolar flap. Plast. Reconstr. Surg. 81:74, 1988 .

20. Robotti, E., Verna, G., Fraccalvieri, M., and Bocchiotti, M. A. Distally based fasciocutaneous flaps: A versatile option for coverage of difficult war wounds of the foot and ankle. Plast. Reconstr. Surg. 101: 1014, 1998.

21. El-Shazly M, Yassin 0, Kamal A, et al. Soft tissue defects of the heel: A surgical reconstruction algorithm based on a retrospective cohort study. J
Foot Ankle Surg. 2008:47:145-152.

22. Shanahan RE, Gingrass RP. Medial plantar sensory flap for coverage of heel defects. Plast Reconstr Surg. 1979;64:295-298.

23. Yildirim S, Akan M, Ako " $z$ T. Soft-tissue reconstruction of the foot with distally based neurocutaneous flaps in diabetic patients. Ann Plast Surg. 2002;48:258-264.

24. Follmar KE, Baccarani A, Baumeister SP, Levin LS, Erdmann D. The distally based sural flap. Plast Reconstr Surg. 2007;119: 138e-148e.

25. Chen SL, Chen TM, Chou TD, Chang SC, Wang HJ. Distally based sural fasciomusculocutaneous flap for chronic calcaneal osteomyelitis in diabetic patients. Ann Plast Surg. 2005; 54:44-48.

26. Eginton MT, Brown KR, Seabrook GR, Towne JB, Cambria RA. A prospective randomized evaluation of negative-pressure wound dressings for diabetic foot wounds. Ann Vasc Surg. 2003 Nov; 17(6):645-9.

27. Schwabegger AH, Shafighi M, Gurunluoglu $R$. Versatility of the abductor hallucis muscle as a conjoined or distally-based flap. J Trauma. 2005 0ct:59(4):1007-11.

28. Demirseren ME, Gokrem S, Can Z. Reappraisal of island modifications of lateral calcaneal artery skin flap. Plast Reconstr Surg. 2004 Apr 1;113(4):1167-74

29. Schaverien MV, Hamilton SA, Fairburn N, Rao P, Quaba $A A$. Lower limb reconstruction using the islanded posterior tibial artery perforator flap. Plast Reconstr Surg. 2010 Jun;125(6):1735-43.

30. Demirtas Y, Neimetzade T, Kelahmetoglu 0, Guneren E. Comparison of free muscle and perforator skin flaps for soft tissue reconstruction of the foot and ankle. Foot Ankle Int. 2010 Jan;31(1):53-8.

31. Chung MS, Baek GH, Gong HS, Rhee SH, Oh WS, Kim $\mathrm{MB}$, Lee KH, Kim TW, Lee YH. Lateral calcaneal artery adipofascial flap for reconstruction of the posterior heel of the foot. Clin Orthop Surg. 2009 Mar;1(1):1-5. Epub 2009 Feb 6.

32. Langstein HN, Chang DW, Miller MJ, Evans GR, Reece GP, Kroll SS, Robb GL. Limb salvage for soft-tissue 
malignancies of the foot: an evaluation of free-tissue transfer. Plast Reconstr Surg. 2002 Jan;109(1):152-9.

33. Hayashi A, Maruyama Y. Lateral calcaneal V-Y advancement flap for repair of posterior heel defects. Plast Reconstr Surg. 1999 Feb;103(2):577-80.

34. Hamdi MF, Khlifi A. Lateral supramalleolar flap for coverage of ankle and foot defects in children. J Foot Ankle Surg. 2012 Jan-Feb;51(1):106-9

35. Lin SD, Chou CK, Yang CC, Lai CS. Reconstruction of plantar heel defect using reinnervated, skin-grafted flexor digitorum brevis flap. Br J Plast Surg. 1991 FebMar;44(2):109-12.

36. Baltensperger MM, Ganzoni N, Jirecek V, Meyer VE. The extensor digitorum brevis island flap: possible applications based on anatomy. Plast Reconstr Surg. 1998 Jan;101(1):107-13.
37. Gang RK. Reconstruction of soft-tissue defect of the posterior heel with a lateral calcaneal artery island flap. Plast Reconstr Surg. 1987 Mar;79(3):415-21.

38. Benito-Ruiz J, Yoon T, Guisantes-Pintos E, Monner J, Serra-Renom JM. Reconstruction of soft-tissue defects of the heel with local fasciocutaneous flaps. Ann Plast Surg. 2004 Apr;52(4):380-4.

39. Wei JW, Dong ZG, Ni JD, Liu LH, Luo SH, Luo ZB, Zheng $L, H e$ AY. Influence of flap factors on partial necrosis of reverse sural artery flap: a study of 179 consecutive flaps. J Trauma Acute Care Surg. 2012 $\operatorname{Mar} ; 72(3): 744-50$.

40. Attinger, Christopher E. M.D.; Ducic, Ivica M.D., Ph.D. Cooper, Paul M.D.; Zelen, Charles M. D.P.M. The Role of Intrinsic Muscle Flaps of the Foot for Bone Coverage in Foot and Ankle Defects in Diabetic and Nondiabetic Patients. Plast Reconstr Surg. 2002 Sep;110(4):10491054

\section{AUTHOR(S):}

1. DR. MUHAMMAD RIZWAN ASLAM MBBS, FCPS(Surg), FCPS(Plast) Consultant Plastic \& Recon. Surgeon Combined Military Hospital, Multan.

2. DR. AIZAZ SALEEM KHAN MBBS, FCPS(Surg), FCPS(Ortho) Consultant Orthopedic Surgeon Combined Military Hospital, Multan.

3. DR. IBRAHIM FAROOQ PASHA MBBS, FCPS(Ortho) Consultant Orthopedic Surgeon Combined Military Hospital, Peshawer.
4. Dr. Rizwan UIIah Taj MBBS, FCPS(Ortho) Consultant General Surgeon Combined Military Hospital, Multan.

Correspondence Address:

Lt. Col, Dr. Muhammad Rizwan Aslam MBBS, FCPS(Surg), FCPS(Plast) Consultant Plastic \& Reconstructive Surgeon Combined Military Hospital, Multan. rafeh28@yahoo.com

Article received on: 28/12/2012 Accepted for Publication: 29/01/2013 Received after proof reading: 21/05/2013

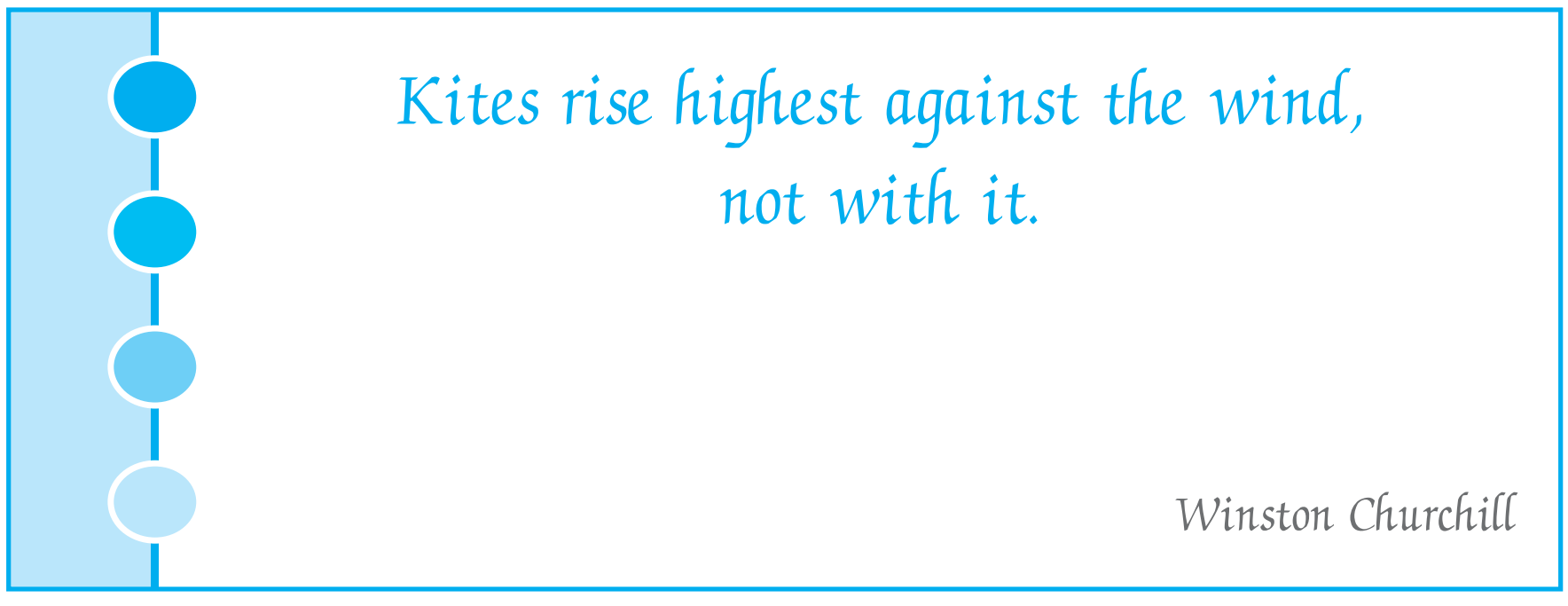

